\title{
Identification by PCR of Helicobacter pylori in subgingival plaque of adult periodontitis patients
}

\author{
M. P. RIGGIO and A. LENNON \\ Infection Research Group, University of Glasgow Dental School, 378 Sauchiehall Street, Glasgow G2 3JZ
}

\begin{abstract}
The PCR was used to detect the presence of Helicobacter pylori in subgingival plaque samples from patients with adult periodontitis. Primers based upon the 16S ribosomal RNA (rRNA) gene sequence of $H$. pylori were used in a single round of PCR to amplify a 295-bp DNA fragment and the identity of the amplified products was confirmed by Southern blot hybridisation to a digoxigenin-labelled $H$. pylori probe. Further confirmation of product identity was obtained by DNA sequencing of a proportion of the amplified products. The assay was demonstrated to be specific for $H$. pylori with a lower limit of detection of $100 \mathrm{fg}$ of bacterial genomic DNA. In all, 73 samples from 29 patients were analysed, of which $24(33 \%)$ were $H$. pylori-positive by PCR; the proportion of patients carrying $H$. pylori in at least one sampled site was $38 \%$ (11 of 29). This is the first study to demonstrate the presence of $\boldsymbol{H}$. pylori in the subgingival plaque of patients with adult periodontitis and indicates that, in this patient group at least, subgingival plaque may be a reservoir for $H$. pylori infection.
\end{abstract}

\section{Introduction}

Helicobacter pylori is a gram-negative, micro-aerophilic bacterium which is recognised as being an aetiological agent of chronic active gastritis and peptic ulcer disease [1-3], and has also been associated with gastric cancer $[4,5]$. In the Western world, average $H$. pylori infection rates in healthy adults are estimated to be between 10 and $40 \%$, whereas patients with gastritis or gastric and duodenal ulceration have infection rates of $80-100 \%$ [6]. The prevalence of $H$. pylori infection has been shown to increase with age, with an estimated $50-60 \%$ of people over 55 years old being infected, compared with only $10-20 \%$ of young adults $[7,8]$. In developing countries, where sanitation is poor, up to $50 \%$ of children are infected by 5 years of age $[9,10]$.

The mode of transmission of $H$. pylori is poorly understood, although it appears that oral-oral and faecal-oral routes are possible [11]. Evidence exists for possible oral transmission from person-to-person $[12,13]$ and faecal-oral transmission is thought to be particularly prevalent in developing countries, although the organism is rarely isolated from faeces [13]. Transmission of $H$. pylori in gastric juice as a result of epidemic childhood vomiting has also been

Received 26 May 1998; revised version accepted 13 July 1998.

Corresponding author: Dr M. P. Riggio. proposed [14]. The natural reservoir for $H$. pylori is unknown, although the oral cavity has been the focus of much attention in this respect. However, controversy surrounds the hypothesis that the oral cavity may be a permanent reservoir for H. pylori. The presence of $H$. pylori in dental plaque of patients with and without stomach disorders has been investigated by culture and PCR methods. Most studies have failed to isolate $H$. pylori by culture from dental plaque of patients undergoing endoscopy [15-19]. PCR analysis of dental plaque from endoscopy patients has yielded more conflicting data, with $H$. pylori found frequently in some studies $[15,20,21]$, but absent or found at very low frequency in other studies $[16,22]$. In the dental plaque of healthy subjects, culture methods have detected $H$. pylori at high frequency in a single study [23], and PCR has detected the organism at high frequency in only one study [15]. In symptomatic individuals, PCR has detected H. pylori in saliva [2426], whereas culture methods have very rarely isolated H. pylori from saliva [27]. Clearly, the prevalence of $H$. pylori will vary amongst different population groups and this may account partly for the conflicting data presented in the literature on the presence of this organism in the oral cavity.

Previous studies have examined mostly either supragingival plaque alone or supragingival mixed with subgingival plaque from the gingival crevice of periodontally healthy individuals for the presence of 
H. pylori. As Glasgow has a rate of $H$. pylori infection $(70 \%)$ that is significantly higher than the UK average, this study aimed to investigate the possible presence of $H$. pylori in subgingival plaque of adult periodontitis patients attending Glasgow Dental Hospital for treatment. Only one previous study has reported the use of PCR to attempt detection of $H$. pylori in the subgingival plaque of adult periodontitis patients, but the organism was not found in any of the 336 samples analysed [28].

\section{Materials and methods}

\section{Bacterial culture and genomic DNA purification}

H. pylori (ATCC 43504) was inoculated on to tryptic soy agar plates containing horse blood $7 \% \mathrm{v} / \mathrm{v}$, triphenyl tetrazolium chloride $0.1 \% \mathrm{w} / \mathrm{v}$ and vancomycin $3 \mathrm{mg} / \mathrm{ml}$ and incubated at $37^{\circ} \mathrm{C}$ in jars containing an atmosphere with increased $\mathrm{CO}_{2}$ for 3-5 days. Bacterial growth from these plates was scraped off and genomic DNA was extracted with the Puregene DNA Purification Kit for gram-negative bacteria (Flowgen Instruments, Lichfield).

\section{Sample details}

Subjects were patients with chronic adult periodontitis who were newly referred to Glasgow Dental Hospital. Patients had at least three periodontal pockets with a minimum depth of $5 \mathrm{~mm}$ and bleeding on probing, had not received antibiotic therapy during the preceding 6 months and demonstrated no symptoms of gastritis or peptic ulcer disease. Two-to-four samples were analysed from 29 patients and of the 73 samples analysed, 40 were from 15 males (age range 36-54 years, mean age 45.9 years) and 33 were from 14 females (age range $36-60$ years, mean age 44.1 years). In the male patient group, mean pocket depth of samples analysed was $5.8 \mathrm{~mm}$ (pocket depth range 5-9 $\mathrm{mm}$ ) and for the female patient group mean pocket depth was $6.1 \mathrm{~mm}$ (pocket depth range $5-11 \mathrm{~mm}$ ).

\section{Collection of subgingival plaque samples}

Subgingival plaque samples were collected with a single stroke of a separate sterile curette for each sample to prevent cross-contamination and placed into sterile tubes containing $0.5 \mathrm{ml}$ of freshly prepared Fastidious Anaerobe Broth (Bioconnections, Leeds). Samples were vortex mixed for $30 \mathrm{~s}$ and lysates were prepared for use in PCR by addition of $90 \mu 1$ of subgingival plaque to $10 \mu \mathrm{l}$ of $10 \times$ lysis buffer (100 mM Tris-HCl, pH 8.0; $10 \mathrm{mM}$ EDTA; Triton X$10010 \%$ ) and boiling for $5 \mathrm{~min}$. A $5-\mu \mathrm{l}$ sample of lysate was used in each $\mathrm{PCR}$ reaction and the remainder of the lysates were stored at $-70^{\circ} \mathrm{C}$.

\section{PCR primers}

The primers selected for PCR targeted the $16 \mathrm{~S}$ ribosomal RNA (rRNA) gene of $H$. pylori. A previously published study described the use of primer pair JW21/JW22 for the specific detection of $H$. pylori [29]. The present study used primer JW22 (5'CGTTAGCTGCATTACTGGAGA-3'; nucleotides 830$810)$ but replaced JW21 with primer JW23 (5'-GAGCGCGTAGGCGGGATAGTC-3'; nucleotides 536-556), which lies 156 nucleotides upstream of the JW21 primer sequence in the 16S rRNA gene. Primer JW23 shows more sequence diversity than primer JW21 at its $3^{\prime}$ end with the corresponding region of the $16 \mathrm{~S}$ rRNA genes of other closely related members of the Helicobacter genus and can thus be expected to be no less specific than primer JW21. The expected size of the amplification product obtained with primers JW22/JW23 was 295 bp.

\section{PCR amplification}

PCR amplification was performed in a reaction volume of $50 \mu \mathrm{l}$ consisting of $5 \mu \mathrm{l}$ of subgingival plaque lysate or $1 \mu \mathrm{l}(100 \mathrm{ng})$ of $H$. pylori genomic DNA and either 45 or $49 \mu \mathrm{l}$ of reaction mixture containing $1 \times \mathrm{PCR}$ buffer (10 mM Tris-HCl, $\mathrm{pH} 8.8,1.5 \mathrm{mM} \mathrm{MgCl}_{2}$, Triton $\mathrm{X}-1000.1 \%), 1.0$ unit of Taq DNA polymerase (Pharmacia Biotech, St Albans), $0.2 \mathrm{mM}$ of each deoxynucleotide triphosphate (dATP, dCTP, dGTP, dTTP) and each primer at a concentration of $0.2 \mu \mathrm{M}$. Primers were separated from other reaction components by a layer of wax ('hot start' PCR), preventing the reaction from starting until the wax melted upon commencement of thermal cycling and thus improving the specificity and yield of reaction products. PCR amplification was performed in an OmniGene thermal cycler (Hybaid, Teddington). After an initial denaturation step of $94^{\circ} \mathrm{C}$ for $5 \mathrm{~min}$, there were 40 cycles of denaturation at $94^{\circ} \mathrm{C}$ for $1 \mathrm{~min}$, annealing at $60^{\circ} \mathrm{C}$ for $1 \mathrm{~min}$ and extension at $72^{\circ} \mathrm{C}$ for $1 \mathrm{~min}$, followed by a final extension step at $72^{\circ} \mathrm{C}$ for $10 \mathrm{~min}$. Reaction products were either analysed immediately or stored at $-20^{\circ} \mathrm{C}$ until required.

\section{PCR quality control}

To avoid contamination, stringent procedures were employed when performing PCR. Separate rooms were used for sample preparation, setting up of PCR reactions and post-PCR analysis of reaction products. Filter tips were used at all stages when setting up reactions and positive displacement tips were used for adding sample to the reaction mixtures. Positive and negative controls were included for each set of samples analysed. The positive control used was a standard reaction mixture containing $100 \mathrm{ng}$ of $H$. pylori genomic DNA instead of sample; the negative control contained sterile water instead of sample. A negative control was included for every three samples analysed. 
Agarose gel electrophoresis

A $10-\mu l$ volume of each reaction product was added to $2 \mu \mathrm{l}$ of gel loading dye (bromophenol blue $0.25 \% \mathrm{w} / \mathrm{v}$, glycerol 50\% v/v, $100 \mathrm{mM}$ EDTA, pH 8.0), electrophoresed on an agarose $2 \%$ gel containing ethidium bromide $0.5 \mu \mathrm{g} / \mathrm{ml}$ and visualised on an ultraviolet (UV) transilluminator. A 100-bp DNA ladder (Pharmacia Biotech) was used as a size marker.

\section{Southern blot hybridisation}

Reaction products were electrophoresed on agarose $2 \%$ gels as described above and transferred to positively charged nylon membranes (Boehringer Mannheim, Lewes). Briefly, gels were prepared for transfer by washing in $250 \mathrm{ml}$ of denaturation solution $(0.5 \mathrm{M}$ $\mathrm{NaOH}, 1.5 \mathrm{M} \mathrm{NaCl}$ ) for $2 \times 20 \mathrm{~min}$, followed by washing in $250 \mathrm{ml}$ of neutralisation solution $(0.5 \mathrm{M}$ Tris-HCl, $\mathrm{pH} 7.4,3.0 \mathrm{M} \mathrm{NaCl}$ ) for $2 \times 20 \mathrm{~min}$. DNA was transferred to membranes by means of a capillary blotting unit (Anachem, Luton) with $20 \times \operatorname{SSC}(3.0 \mathrm{M}$ $\mathrm{NaCl}, 0.3 \mathrm{M}$ tri-sodium citrate, $\mathrm{pH} 7.0$ ) as a transfer buffer. After overnight transfer, membranes were rinsed in $2 \times$ SSC and DNA was immobilised to membranes by exposure to an optimal dose of UV energy in a cross-linker (UVC-508; Anachem).

Membranes were hybridised overnight at $68^{\circ} \mathrm{C}$ with the 295-bp H. pylori 16S rRNA PCR product labelled with digoxigenin (DNA Labelling and Detection Kit; Boehringer Mannhein) at $5 \mathrm{ng} / \mathrm{ml}$ in standard hybridisation buffer $5 \times \mathrm{SSC}$, blocking reagent $1 \% \mathrm{w} / \mathrm{v}, \mathrm{N}-$ laurylsarcosine $0.1 \% \mathrm{w} / \mathrm{v}$, SDS $0.02 \% \mathrm{w} / \mathrm{v}$ ). Membranes were rinsed at room temperature in $2 \times$ SSC/SDS $0.1 \%$ for $2 \times 5 \mathrm{~min}$ and then washed under conditions of high stringency at $68^{\circ} \mathrm{C}$ in $0.1 \times \mathrm{SSC} /$ SDS $0.1 \%$ for $2 \times 20 \mathrm{~min}$. Immunological detection of hybridised products was done according to the manufacturer's instructions with an anti-digoxigenin antibody conjugated to alkaline phosphatase, followed by colorimetric detection with 4-nitroblue tetrazolium chloride/5-bromo-4-chloro-3-indolyl-phosphate as a colour substrate.

\section{DNA sequencing}

Selected PCR products were cloned into pCR2.1-TOPO cloning vector with the TOPO TA Cloning Kit (Invitrogen BV, NV Leek, The Netherlands) according to the manufacturer's instructions. Plasmid DNA from recombinant clones was purified with the Wizard Plus SV Minipreps DNA Purification System (Promega Corporation, Southampton). Sequencing reactions were performed with Thermo Sequenase Fluorescent Labelled Primer Cycle Sequencing Kit with 7-deazadGTP (Amersham Pharmacia Biotech, Little Chalfont) and IRD800-labelled M13 universal (-21) primer. Sequence data were collected and analysed by an LICOR 4200S automated sequencing system (MWGBiotech, Milton Keynes).

\section{Results}

\section{Specificity of the H. pylori PCR assay}

The H. pylori PCR assay was performed with $100 \mathrm{ng}$ of genomic DNA from each of the oral species Porphyromonas gingivalis (ATCC 33277), Prevotella intermedia (ATCC 25611), Pr. nigrescens (ATCC 33563), Actinobacillus actinomycetemcomitans (ATCC 33384), Haemophilus aphrophilus (ATCC 33389), Hae. paraphrophilus (ATCC 29241), Bacteroides forsythus (ATCC 43037), Fusobacterium nucleatum (ATCC 25586), Eikenella corrodens (ATCC 23834), Streptococcus mutans (ATCC 25175), S. mitis (ATCC 49456) and Candida albicans (NCTC 3153), as well as genomic DNA from Escherichia coli (ATCC 11775). Genomic DNA from the closely related species $H$. cinaedi (ATCC 35683), H. mustelae (ATCC 43772), $H$. fennelliae (ATCC 35684), Campylobacter jejuni (ATCC 33560) and C. coli (ATCC 33559) were also tested. No DNA from any of these species was detectable by PCR (results not shown), thus confirming the specificity of the PCR assay for H. pylori.

\section{Sensitivity of the H. pylori PCR assay}

The lower detection limit after 40 cycles of DNA amplification with primers JW22/JW23 was $100 \mathrm{fg}$ of $H$. pylori DNA, which is equivalent to $c .100$ bacterial cells (results not shown).

\section{Detection of $H$. pylori in subgingival plaque samples by PCR}

The PCR assay specific for H. pylori was applied to subgingival plaque samples from periodontal pockets at least $5 \mathrm{~mm}$ in depth from 29 patients with adult periodontitis. Two-to-four subgingival plaque samples from different periodontal pockets were analysed for each patient and the presence of $H$. pylori in a sample was indicated by the amplification of a 295-bp product. H. pylori DNA was detected in $24(33 \%)$ of the 73 samples analysed (14 male, 10 female); $11(38 \%)$ of the 29 patients (6 male, 5 female) harboured H. pylori in at least one analysed site. H. pylori-positive patients harboured the organism in all the subgingival plaque samples analysed. Fig. 1 shows representative results from agarose gel electrophoresis of PCR products from subgingival plaque samples; amplified products were always a single band of the expected size ( $295 \mathrm{bp}$ ) and no non-specific reaction products were seen on any occasion.

\section{Confirmation of product specificity}

The specificity of amplified products was confirmed by Southern blot hybridisation to a digoxigenin-labelled H. pylori 16S rRNA probe (Fig. 2). All samples positive by agarose gel electrophoresis hybridised to the probe, confirming the successful amplification of 


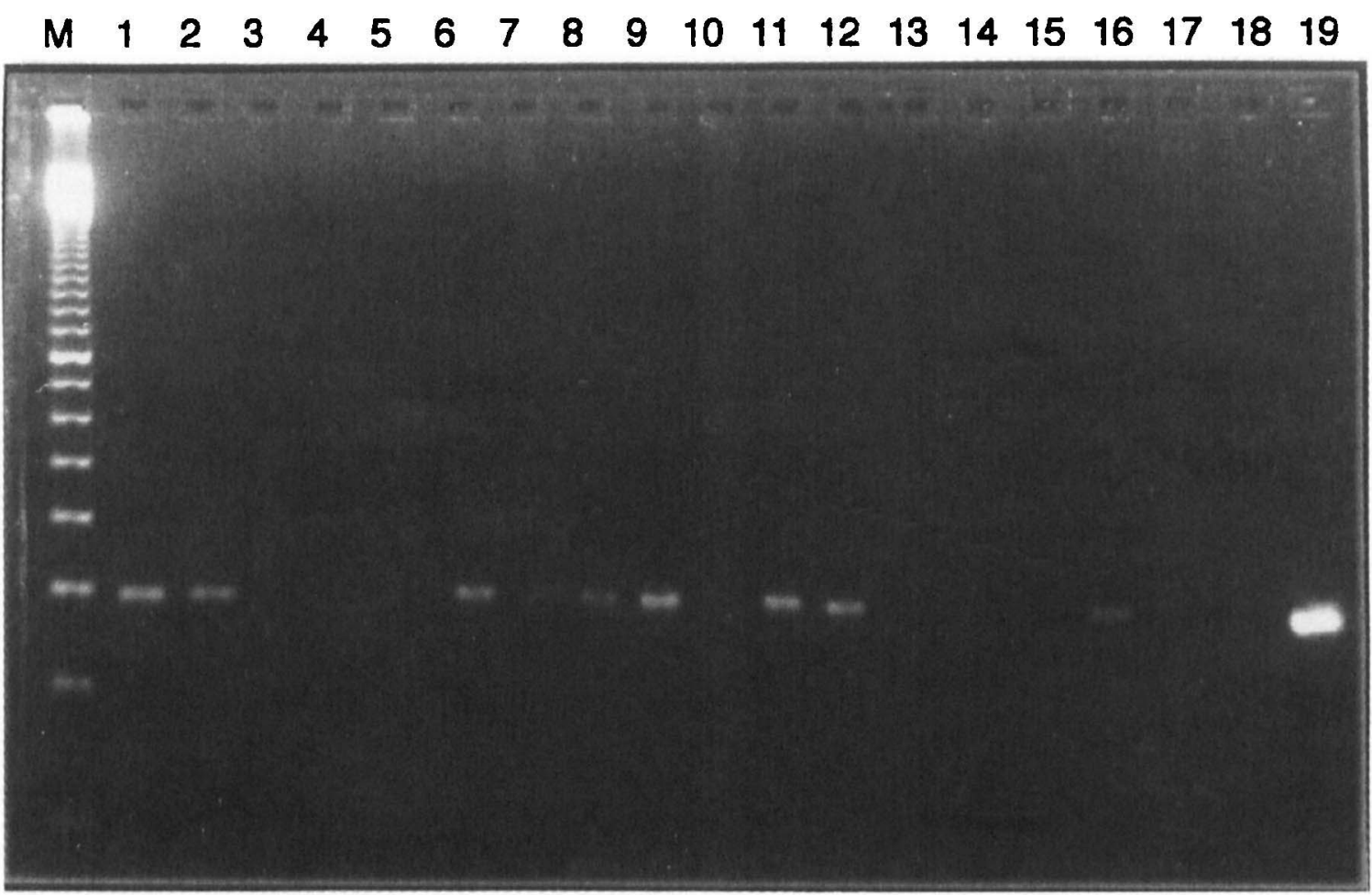

Fig. 1. Agarose $2 \%$ gel electrophoresis of selected products from subgingival plaque samples following PCR with the $H$. pylori-specific primer pair JW22/JW23. Lane M, 100-bp DNA ladder; 1-17, subgingival plaque samples; 18, negative control; 19, positive control. PCR positivity is indicated by the presence of a 295 -bp product.

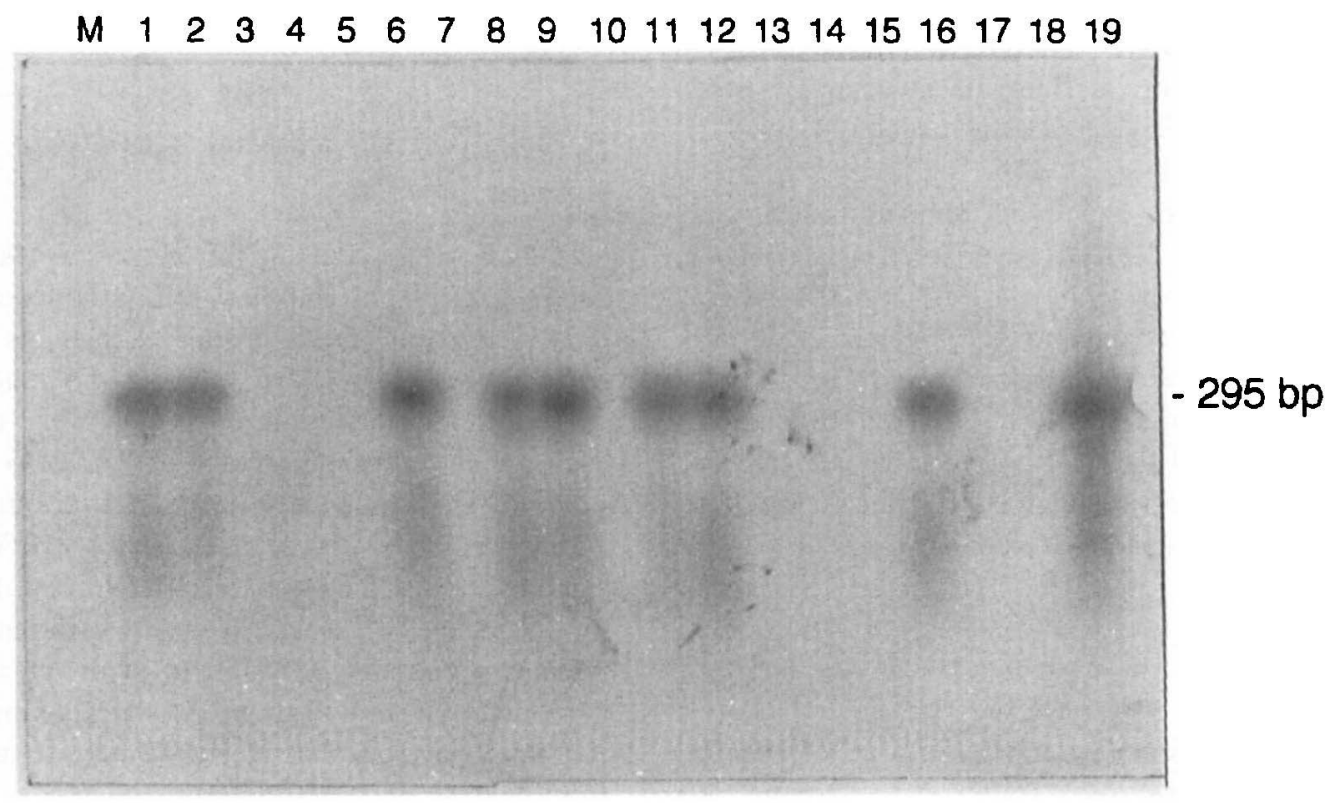

Fig. 2. Corresponding Southern blot hybridisation of the PCR products shown in Fig. 1. The PCR products were hybridised to the 295-bp $H$. pylori positive control 16S rRNA PCR product labelled with digoxigenin.

H. pylori DNA. No samples that were negative by agarose gel electrophoresis hybridised to the probe. Additional confirmation of product specificity was obtained by DNA sequencing of PCR products. Five PCR products were cloned into pCR2.1-TOPO cloning vector and four recombinant clones derived from each cloned product were sequenced. The DNA sequence data demonstrated that all 20 recombinant clones sequenced originated from $H$. pylori DNA, thus further confirming the specificity of the PCR assay.

\section{Discussion}

The purpose of this study was to examine subgingival plaque from adult periodontitis patients for the 
presence of $H$. pylori with an $H$. pylori-specific PCR assay as described previously [29], but with some modifications. Although the primers used in the earlier study were shown to be specific for $H$. pylori at an annealing temperature of $55^{\circ} \mathrm{C}$, in the present study the upstream primer was replaced with another that showed even more specificity at its $5^{\prime}$ end and the annealing temperature was increased from $55^{\circ} \mathrm{C}$ to $60^{\circ} \mathrm{C}$ to further minimise non-specific annealing. The majority of published studies have examined dental plaque from subjects without periodontitis, i.e., supragingival plaque or subgingival plaque from the gingival crevice. A single study has examined subgingival plaque from adult periodontitis patients for $H$. pylori by PCR [28]. In the latter study, in the USA, none of 336 subgingival plaque samples analysed was positive for $H$. pylori. These results are clearly discrepant with the findings of the present study, in which $H$. pylori was found in the subgingival plaque of approximately one-third of the adult periodontitis patients examined. This difference may be attributable to the different population groups examined and also the methods employed for plaque sampling. The authors of the American study conceded that their paper point sampling method may collect less bacteria than the curette sampling method which was used in the present study. This less effective sampling method will undoubtedly affect the detection of $H$. pylori in the periodontal pocket if only low numbers of H. pylori cells are present.

The possible role of the oral cavity as a reservoir for $H$. pylori is a highly controversial issue. While some studies have detected $H$. pylori frequently at sites, such as plaque $[15,20,21]$ and saliva [24-26], in the oral cavity of endoscopy patients by PCR, other studies have either failed to detect the organism or found it at very low frequency $[16,22]$. Clearly, such conflicting data can be attributed in part to differences in the populations examined, as $H$. pylori is generally found at a higher prevalence in the populations of developing countries. It is not known whether $H$. pylori can colonise the oral cavity or is transient as a result of gastric reflux. Genetic typing studies on isolates obtained from both the oral cavity and stomach of patients have shown that strains from these two sites tend to be identical, although different strains are harboured by different individuals [19, 30]. The identification of identical strains of $H$. pylori in stomach and oral samples of individuals can be interpreted in two ways. Firstly, such observations could lend credence to the theory that $H$. pylori may be only a transient member of the oral cavity as it may be present in the oral cavity as a direct result of gastric reflux. Alternatively it can be speculated that oral sites such as dental plaque may be a reservoir for gastric re-infection by $H$. pylori. PCR has demonstrated the presence of $H$. pylori in the saliva of patients whose gastric biopsies were negative for $H$. pylori and lack of correlation between gastric symptoms and the presence of $H$. pylori in the oral cavity was also observed [25]. These observations led the authors to suggest that oral colonisation by $H$. pylori may precede gastric infection and that saliva may also be a reservoir for gastric re-infection by $H$. pylori. Claims that $H$. pylori is a permanent member of the oral cavity that can cause gastric re-infection, and inevitably person-to-person transmission, can be substantiated only by recovery of viable $H$. pylori from the oral cavity, which has rarely been accomplished. Reasons for the general inability to culture $H$. pylori from the oral cavity are difficult to assign with any certainty, but could include the presence of the organism in a coccoid form that is non-culturable in vitro [31]. Experimental evidence has been presented which suggests that the coccoid form of $H$. pylori may be viable $[32,33]$. It has been postulated that $H$. pylori may exist in the environment in a nonculturable coccoid form that can revert to a replicative form in vivo following ingestion by a mammalian host [34], but no conclusive evidence exists to support this hypothesis. If this hypothesis could be proved it would strengthen the notion of water and food as important reservoirs for $H$. pylori.

Previous attempts to detect $H$. pylori in the oral cavity have focused primarily on dental plaque and, more rarely, saliva as target specimens. Recent studies have investigated other oral sites for the potential presence of $H$. pylori. H. pylori was not detected in any of 20 salivary lympho-epithelial lesions analysed by nested PCR [35]. In another study, nested PCR was used in the attempted detection of $H$. pylori in specimens from several sites in the oral cavity, i.e., lingual, buccal and labial mucosa, hard and soft palate, oral vestibule and gingiva [36]. Of the 161 patients examined, only $21(13 \%)$ were PCR-positive for $H$. pylori and no site was identified as preferentially harbouring the organism; furthermore, no association was found between the presence of $H$. pylori and ulcerated (recurrent aphthous ulcers, oral erosive lichen planus, lingual ulcers) versus non-ulcerated lesions. PCR has also been used to identify $H$. pylori in the cheeks of dyspeptic patients [37]. H. pylori has been detected in six $(21 \%)$ of 29 oral mucosal ulcers examined by in-situ hybridisation [38].

The majority of published studies that have identified $H$. pylori in oral samples have used two rounds of PCR for increased sensitivity. It is important to note that, in the present study, $H$. pylori DNA was amplified from subgingival plaque samples with a single round of PCR, with a lower detection limit of $100 \mathrm{fg}$ of $H$. pylori DNA (c. 100 bacterial cells). Whereas two rounds of PCR can generally detect between one and 10 bacterial cells, the clinical significance of such small numbers of bacteria in clinical samples remains questionable. Although the PCR assay used in the present study is only semiquantitative, many of the PCR-positive subgingival plaque samples analysed gave a signal intensity of a 
magnitude where it could be expected that $H$. pylori is present in numbers above the lower detection limit of culture methods. Future studies will aim to establish whether $H$. pylori in PCR-positive subgingival plaque samples from adult periodontitis patients can indeed be isolated by culture or if organisms are present in a non-culturable form.

\section{References}

1. Lee A, Fox J, Hazell S. Pathogenicity of Helicobacter pylori: a perspective. Infect Immun 1993; 61: 1601-1610.

2. Taylor DN, Blaser MJ. The epidemiology of Helicobacter pylori infection. Epidemiol Rev 1991; 13: 42-59.

3. Andersen LP, Holck S, Povlsen CO, Elsborg L, Justesen T Campylobacter pyloridis in peptic ulcer disease. I. Gastric and duodenal infection caused by $C$. pyloridis: histopathologic and microbiologic findings. Scand $J$ Gastroenterol 1987; 22 219-224.

4. Forman D, Newell DG, Fullerton F et al. Association between infection with Helicobacter pylori and risk of gastric cancer: evidence from a prospective investigation. $B M J$ 1991; 302: 1302-1305.

5. Parsonnet J, Vandersteen D, Goates J, Sibley RK, Pritikin J Chang Y. Helicobacter pylori infection in intestinal- and diffuse-type gastric adenocarcinomas. J Natl Cancer Inst 1991; 83: $640-643$.

6. Megraud F. Epidemiology of Helicobacter pylori infection. Gastroenterol Clin North Am 1993; 22: 73-88.

7. Veldhuyzen van Zanten SJO, Pollak PT, Best LM, Bezanson GS, Marrie T. Increasing prevalence of Helicobacter pylori infection with age: continuous risk of infection in adults rather than cohort effect. $J$ Infect Dis 1994; 169: 434-437.

8. Kosunen TU, Höök J, Rautelin HI, Myllylä G. Age-dependent increase of Campylobacter pylori antibodies in blood donors. Scand J Gastroenterol 1989; 24: 110-114.

9. Mitchell HM, Li YY, $\mathrm{Hu}$ PJ et al. Epidemiology of Helicobacter pylori in Southern China: identification of early childhood as the critical period for acquisition. $J$ Infect Dis 1992; 166: 149-153.

10. Holcombe C. Helicobacter pylori: the African enigma. Gut 1992; 33: 429-431.

11. Goodman KJ, Correa P. The transmission of Helicobacter pylori. A critical review of the evidence. Int J Epidemiol 1995; 24: $875-887$.

12. Drumm B, Perez-Perez GI, Blaser MJ, Sherman PM. Intrafamilial clustering of Helicobacter pylori infection. $N$ Engl J Med 1990; 322: 359-363.

13. Li C, Ha T, Ferguson DA et al. A newly developed PCR assay of $H$. pylori in gastric biopsy, saliva, and feces. Evidence of high prevalence of $H$. pylori in saliva supports oral transmission. Dig Dis Sci 1996; 41: 2142-2149.

14. Axon ATR. The transmission of Helicobacter pylori: which theory fits the facts? Eur $J$ Gastroenterol Hepatol 1996; 8: $1-2$.

15. Banatvala N, Romero Lopez C, Owen RJ et al. Use of the polymerase chain reaction to detect Helicobacter pylori in the dental plaque of healthy and symptomatic individuals. Microb Ecol Health Dis 1994; 7: 1-8.

16. Bickley J, Owen RJ, Fraser AG, Pounder RE. Evaluation of the polymerase chain reaction for detecting the urease $\mathrm{C}$ gene of Helicobacter pylori in gastric biopsy samples and dental plaque. J Med Microbiol 1993; 39: 338-344.

17. Krajden S, Fuksa M, Anderson $\mathrm{J}$ et al. Examination of human stomach biopsies, saliva, and dental plaque for Campylobacter pylori. J Clin Microbiol 1989; 27: 1397-1398.

18. Bernander S, Dalen J, Gastrin B, Hedenborg L, Lamke LO, Ohrn R. Absence of Helicobacter pylori in dental plaques in Helicobacter pylori positive dyspeptic patients. Eur J Clin Microbiol Infect Dis 1993; 12: 282-285.

19. Khandaker K, Palmer KR, Eastwood MA, Scott AC, Desai M, Owen RJ. DNA fingerprints of Helicobacter pylori from mouth and antrum of patients with chronic ulcer dyspepsia. Lancet 1993; 342: 751

20. Nguyen AMH, Engstrand L, Genta RM, Graham DY, El Zaatari FAK. Detection of Helicobacter pylori in dental plaque by reverse transcription-polymerase chain reaction. $J$ Clin Microbiol 1993; 31: 783-787.

21. Yang HT. [Nested polymerase chain reaction in detection of Helicobacter pylori in human dental plaque.] Chung Hua I Hsueh Tsa Chih 1993; 73: 750-752.

22. Hardo PG, Tugnait A, Hassan F et al. Helicobacter pylori infection and dental care. Gut 1995; 37: 44-46.

23. Majmudar P, Shah SM, Dhunjibhoy KR, Desai HG. Incidence of Helicobacter pylori in dental plaques in healthy volunteers. Ind $J$ Gastroenterol 1990; 9: 271-272.

24. Hammar M, Tyszkiewicz T, Wadström T, O'Toole PW. Rapid detection of Helicobacter pylori in gastric biopsy material by polymerase chain reaction. J Clin Microbiol 1992; 30: 54-58.

25. Li C, Musich PR, Ha T et al. High prevalence of Helicobacter pylori in saliva demonstrated by a novel PCR assay. $J$ Clin Pathol 1995; 48: 662-666.

26. Shimada $\mathrm{T}$, Ogura $\mathrm{K}$, Ota $\mathrm{S}$ et al. Identification of Helicobacter pylori in gastric specimens, gastric juice, saliva, and faeces of Japanese patients. Lancet 1994; 343: 1636-1637.

27. Ferguson DA, Li C, Patel NR, Mayberry WR, Chi DS, Thoma E. Isolation of Helicobacter pylori from saliva. $J$ Clin Microbiol 1993; 31: 2802-2804.

28. Asikainen S, Chen C, Slots J. Absence of Helicobacter pylori in subgingival samples determined by polymerase chain reaction. Oral Microbiol Immunol 1994; 9: 318-320.

29. Weiss J, Mecca J, Da Silva E, Gassner D. Comparison of PCR and other diagnostic techniques for detection of Helicobacter pylori infection in dyspeptic patients. J Clin Microbiol 1994; 32: $1663-1668$

30. Shames B, Krajden S, Fuksa M, Babida C, Penner JL. Evidence for the occurrence of the same strain of Campylobacter pylori in the stomach and dental plaque. $J$ Clin Microbiol 1989; 27: 2849-2850.

31. Cellini L, Allocati N, Di Campli E, Dainelli B. Helicobacter pylori - a fickle germ. Microbiol Immunol 1994; 38: 25-30.

32. Cellini L, Allocati N, Angelucci D et al. Coccoid Helicobacter pylori not culturable in vitro reverts in mice. Microbiol Immunol 1994; 38: 843-850.

33. Hua J, Ho B. Is the coccoid form of Helicobacter pylori viable? Microbios 1996; 87: 103-112.

34. Fox JG. Non-human reservoirs of Helicobacter pylori. Aliment Pharmacol Ther 1995; 9 Suppl 2: 93-103.

35. Jordan RCK, Diss TC, Millson C, Wilson M, Speight PM Absence of Helicobacter pylori DNA in salivary lymphoepithelial lesions. J Oral Pathol Med 1997; 26: 454-457.

36. Mravak-Stipetic M, Gall-Trošelj K, Lukac J, Kusic Z, Pavelic $\mathrm{K}$, Pavelic J. Detection of Helicobacter pylori in various oral lesions by nested polymerase chain reaction (PCR). $J$ Oral Pathol Med 1998; 27: 1-3.

37. Namavar F, Roosendaal R, Kuipers EJ et al. Presence of Helicobacter pylori in the oral cavity, oesophagus, stomach and faeces of patients with gastritis. Eur J Clin Microbiol Infect Dis 1995; 14: 234-237.

38. Leimola-Virtanen R, Happonen R-P, Syrjänen SM. Cytomegalovirus (CMV) and Helicobacter pylori (HP) found in oral mucosal ulcers. J Oral Pathol Med 1995; 24: 14-17. 